\title{
A forma atravessada na garganta: metasonetos de Daniel Jonas e de Paulo Henriques Britto
}

\author{
Roberto Bezerra de Menezes*
}

\section{Resumo}

O surgimento do soneto como forma literária remonta ao século XIII, período em que, ao sul da Itália, nomeadamente a região da Sicília, era larga a influência da lírica de origem provençal. De apelo matemático, a invenção do soneto é atribuída a Giacomo da Lentini, chefe da escola siciliana do Sacro Imperador Romano Frederico II. O presente texto tem como objetivo principal a justaposição de duas poéticas, a do português Daniel Jonas e a do brasileiro Paulo Henriques Britto, de modo a fazer ressaltar as distinções no tratamento metapoético dispensado ao soneto e a outras formas que dele derivam.

Palavras-chave: Soneto. Poesia Portuguesa. Poesia Brasileira. Modernidade. Metapoesia.

\footnotetext{
Universidade Federal de Minas Gerais (UFMG). Mestre em Literatura Comparada pelo Programa de Pós-Graduação em Letras da Universidade Federal do Ceará (UFC) e doutorado em Estudos Literários pela Universidade Federal de Minas Gerais UFMG. Atualmente, é bolsista de Pós-Doutorado (PNPD/CAPES) junto ao Programa de Pós-Graduação em Estudos Literários - Pós-Lit/UFMG. ORCID: https://orcid.org/0000-0002-9504-5388.
} 


\section{La forme croisée dans la gorge: métasonètes de Daniel Jonas et Paulo Henriques Britto}

\section{Résumé}

L'émergence du sonnet comme forme littéraire remonte au $\mathrm{XIII}^{\mathrm{e}}$ siècle, une période où, dans le sud de l'Italie, à savoir la région de la Sicile, l'influence du lyrique d'origine provençale était large. D'un attrait mathématique, l'invention du sonnet est attribuée à Giacomo da Lentini, chef de l'école sicilienne du saint empereur romain Frédéric II. L'objectif principal de ce texte est la juxtaposition de deux poétiques, celle du Portugais Daniel Jonas et celle du Brésilien Paulo Henriques Britto, afin de mettre en évidence les distinctions dans le traitement métapoétique du sonnet et des autres formes qui en découlent. Mots-clés: Sonnet. Poésie Portugaise. Poésie Brésilienne. Modernité. Métapoésie.

Recebido em: 30/09/2020 // Aceito em: 21/11/2020 
un sonnet sans défaut vaut seul un long poème

Nicolas Boileau-Despreaux

\section{O caminho inicial}

O surgimento do soneto como forma literária remonta ao século XIII, período em que, ao sul da Itália, nomeadamente a região da Sicília, era larga a influência da lírica de origem provençal. Segundo Erich Auerbach (2015, p. 203), foram Frederico II (da casa alemã dos Hohenstaufen), seus filhos e sua corte que

imitaram a forma principal da poesia provençal, a grande canção de amor, e inventaram, a par dela, uma forma mais breve e mais concisa, que se tornou a forma lírica mais usual da poesia lírica italiana e que, mais tarde, foi imitada em toda a Europa: o soneto, poema de catorze versos de dez sílabas, composto de duas quadras e de dois tercetos sobre duas rimas para os quartetos e três para os tercetos (por exemplo, ABBA ABBA CDE EDC).

Sobrevivendo ao desaparecimento da família Hohenstaufen, o soneto passou a ser visto como uma expressão "seca e burguesa" (AUERBACH, 2015, p. 203), migrando para o norte da Itália, região onde surgiu Dante Alighieri. Mas é somente no século XIV que conhecemos aquele que tornou o soneto uma das formas mais cultuadas nas gerações seguintes, cuja influência só arrefeceu com o surgimento do Romantismo: Petrarca. Ainda que ele preferisse elaborar suas composições em latim, língua de Cícero e Virgílio que almejava imitar, sua fama maior se deve aos 350 poemas escritos em dialeto florentino e reunidos sob o título Cancioneiro, constituído quase todo de sonetos 
que "nos revelam [...] os movimentos de uma alma inquieta, ao mesmo tempo altiva e ansiosa, que adorava a Antiguidade e era no entanto cristã, que amava o mundo e a glória, mas que se desencantava rapidamente e buscava a solidão e a morte". (AUERBACH, 2015, p. 211).

Em língua vernácula, encontramos em Luís de Camões a continuação da prática do soneto nos moldes petrarquianos, sendo considerado o mestre em língua portuguesa pela excelência com que desenvolveu suas peças líricas. A apropriação e a refundação de muitos dos versos de Petrarca é atividade frequente e a partir deles Camões pode oferecer uma leitura da tradição aliada ao desenvolvimento de seu talento individual (ELIOT, 1989), como é exemplo o soneto "Um mover d'olhos, brando e piadoso" (CAMÕES, 1980, p. 95), cuja estrutura se apoia no soneto "Grazie ch'a pochi il ciel largo destina", de Petrarca, mas é elaborado com expressões originais.

Depois de Camões, encontramos outros autores que, em Portugal, recorreram à forma soneto para a composição lírica. Podemos referir muito brevemente dois casos que, junto a Camões, formam uma espécie de trinca de sonetistas portugueses. O primeiro deles é Bocage, erroneamente tido por representante do período áureo do Arcadismo no século XVIII, uma vez que sua poesia se volta mais para a pequena burguesia que para a aristocracia da Nova Arcádia, para quem dirigia suas sátiras afiadas. Bocage era grande cultor de Camões, de quem guardou o apuro formal e a quem dedicou um de seus melhores sonetos: "Camões, grande Camões, quão semelhante/ Acho teu fado ao meu, quando os cotejo!"” (BOCAGE, 1985, p. 47).

O segundo caso é Antero de Quental, poeta açoriano que, em Coimbra, se colocou frontalmente a par dos assuntos políticos 
da época (Questão Coimbrã), mas que, em sua obra Sonetos, não deixou de tocar em questões metafísicas como a morte e Deus, moldadas pelo enquadramento da forma fixa e reveladora de um sujeito pessimista. Mesmo com o recurso à forma fixa, Quental pode praticar essa liberdade na expressão. Sobre essa tríade sonetista, António José Saraiva nos diz que o "soneto já tinha sido em Camões um género literário adaptado à reflexão; em Bocage é exclamativo e patético. Antero recebeu a herança destes dois mestres, inovando o assunto." (1999, p. 125).

Daniel Jonas, por sua vez, é autor de nove livros de poesia: O corpo está com o rei (1997), Moça formosa, lençóis de veludo (2002), Os fantasmas inquilinos (2005), Sonótono (2007, Prêmio PEN de Poesia), Passageiro frequente (2013), Nó sonetos (2014, Grande Prémio de Poesia Teixeira de Pascoaes da Associação Portuguesa de Escritores), Bisonte (2016), Canícula (2017) e Oblívio (2017, Grande Prémio da Literatura dst). Como dramaturgo, publicou Nenhures (2008) e escreveu Estocolmo, Reféns e o libreto Still Frank, todos encenados pela companhia Teatro Bruto. Cursou mestrado em Teoria da Literatura pela Universidade de Lisboa, com uma dissertação sobre o poeta inglês John Milton, da qual resultou a tradução de Paraíso perdido, publicada também no Brasil pela Editora 34 (2015). Além de Milton, traduziu William Shakespeare, Luigi Pirandello, J.-K. Huysmans, John Berryman, Charles Dickens, Malcolm Lowry, Henry James e William Wordsworth.

Dos livros de poesia acima mencionados, três são totalmente compostos por sonetos: Sonótono, Nó e Oblívio. De acordo com o autor, em entrevista a Joana Emídio Marques, foi com John Milton que "aprend[eu] a cultivar o soneto" (2017, s.p.), afirmação esta que nos permite identificar uma clara 
confluência entre os ofícios de leitor/tradutor e de escritor. Sabe-se que Milton é diretamente influenciado pela tradição shakespereana do soneto - recorde-se a homenagem ao mestre com o poema "On Shakespeare" (1968, p. 123) -, ainda que tenha escrito sonetos em língua italiana e com clara dicção petrarquiana, como é exemplo o "Sonnet I" (1968, p. 90). Daniel Jonas, por sua vez, vem a marcar uma diferença em relação à tradição portuguesa cuja influência era pautada primordialmente no soneto italiano de Petrarca, uma vez que se coloca consciente dessas duas linhagens a que fará referência tanto no nível formal quando nos temas tratados.

Assim como em Portugal, no Brasil o soneto também nasce da influência da linhagem petrarquiana, notadamente pela via medieval portuguesa. Entre os nomes com maior destaque, podemos citar as figuras de Olavo Bilac e Vinícius de Moraes, sem esquecer as contribuições de outros poetas importantes para a construção da poesia brasileira, como Gregório de Matos, Tomás António Gonzaga, Augusto dos Anjos e Carlos Drummond de Andrade, por exemplo.

Paulo Henriques Britto, por seu turno, se insere nessa linhagem que tem interesse no limite criativo da forma poemática soneto, dialogando com nomes como Bilac, referenciado diretamente em seu livro Tarde, por exemplo. É autor dos livros de poesia Liturgia da matéria (1982), Mínima lírica (1989), Trovar claro (1997), Macau (2003), Tarde (2007), Formas do nada (2012) e, mais recentemente, Nenhum mistério (2018). Como Jonas, Britto também é tradutor de textos de língua inglesa, tendo sido responsável pelas edições mais recentes de Elizabeth Bishop, Frank O'Hara, Thomas Pynchon e Wallace Stevens, por exemplo. Além disso, como professor da PUC-Rio, 
Britto se dedica a refletir academicamente sobre a prática da tradução, em especial a tradução de poesia.

Britto recorre ao soneto em todos os volumes de poesia acima mencionados, com maior ou menor incidência a depender do caso. Vê-se que o soneto não é, como no caso de Jonas, uma diç̧ão escolhida para compor um volume específico que demandasse essa forma. Ao contrário, a forma soneto acompanha toda a produção do autor, com seções de poemas seriados que já no título recuperam e modificam o soneto: "Dez sonetos sentimentais", de Liturgia da matéria, continuada no livro seguinte, Mínima lírica, com os "Dois sonetos sentimentais"; em Trovar claro, o "Sonetilho de verão"; os "Sete sonetos simétricos" e os "Dez sonextóides mancos" de Macau; em Tarde, os "Cinco sonetetos grotescos" e os "Cinco sonetetos trágicos"; Formas do nada, por sua vez, apresenta duas seções do tipo, "Cinco sonetos frívolos" e "Seis sonetos soturnos"; o último livro publicado, Nenhum mistério, apesar de conter vários sonetos e suas variantes, não apresenta nenhuma seção seriada nesses moldes. Percebe-se, a partir dos títulos das seções seriadas, que o autor interfere sobremodo na forma levando-a à indistinção, como ele mesmo revela em entrevista: "Eu gosto de fazer isso, pegar o soneto e esticá-lo até a fronteira do não soneto" (2013a, 11'51').

\section{Daniel Jonas e o soneto}

Em resposta a um inquérito sobre "Poesia e Resistência" - cuja questão era precisamente: "A poesia é uma forma de resistência? Sempre, por definição? Ou apenas em determinados contextos - sociais, políticos, culturais? Como pode resistir a 


\section{A forma atravessada na garganta: metasonetos de Daniel Jonas e de Paulo Henriques Britto}

poesia e a quê?" -, levado a cabo por Ana Luísa Amaral, Joana Matos Frias, Pedro Eiras e Rosa Maria Martelo para o portal do Instituto de Literatura Comparada Margarida Losa, em 2012, Daniel Jonas se utiliza de tal questionamento para inventariar uma reflexão sobre o atual estado das coisas, isto é, o lugar da arte, em especial a poesia, em meio às profundas e céleres mudanças pelas quais o nosso mundo contemporâneo têm passado decorrentes da intensificação da sociedade de consumo. Ele diz:

Não forma de resistência no sentido ideológico — pelo menos não sempre - mas certamente uma resistência da forma, numa altura em que os próprios materiais do seu endosso estão a ser reavaliados pelo contexto cibernético actual (a casa desta resposta [o ambiente on-line] é, aliás, sintoma disso mesmo). Em todo o caso estamos perante um momento evolutivo significativo para o medium, até porque me parece que nos casos em que um livro de poemas não é apenas um fólio com poemas avulsos, a ideia de estrutura e conceito fica abalada pela fragmentação espacial do todo. Diria que a explosão viral nos condena a fazermos arqueologia, recolhendo cacos de vasos e ânforas que são os poemas perdidos desta nossa mega Pompeia (em todo o caso a indústria musical queixa-se do mesmo, ao que parece). Quero com isto dizer que eu próprio ando a equacionar este ofício, perguntando-me se será atilado continuar a fazer coisas como livros, no seu sentido autoral, numa idade em que pouca gente os consome e os consome, diria, holisticamente. Em tempos não distantes um livro com poemas era certamente um enunciado, uma afirmação; hoje não passa de um monte de problemas para toda a gente. Ainda, pois, que um poema seja uma forma de resistência da forma, ela está caduca em relação a uma forma maior, fruto de um outono muito pouco poético. (JONAS, 2012, s.p.)

Repare-se que a discussão sobre o domínio do mundo digital sobre as formas de manifestação e expressão da linguagem 
artística é o ponto central da resposta do poeta. Ele chega mesmo a revelar sua preocupação nesse sentido, colocando o papel do livro enquanto unidade sob discussão. Disso ressalta que, para Jonas, o livro, isto é, a reunião de poemas em um único amontoado de páginas numa determinada sequência, é não a oportunidade de publicar os escritos então prontos, mas o meio para se ter acesso, enquanto leitor, a uma composição com "estrutura" e "conceito", marcando desde já sua posição avessa a certas práticas mais publicitárias que literárias vigorantes nos meios atualmente. Dessa posição particular dá-se já a sentir o perfume anacrônico de que falou António Guerreiro (2014, s.p.), entendendo-se que ele também se manifesta fora do texto.

Ainda um ilustre desconhecido no Brasil ${ }^{1}$, o poeta apresenta em sua poesia uma exuberância vocabular e sintática que encontra explicação na seguinte pergunta retórica: "Que nos resta senão linguagem para povoar o mundo?” (JONAS, 2005, p. 81). É nesse esforço de povoamento do mundo com linguagem que o poeta se dedica a desenvolver uma escrita minuciosamente arquitetada, pois neste mundo não entram as palavras que se lhe não pertençam por mérito.

Sobre o soneto em Daniel Jonas, o crítico António Guerreiro, considerando no horizonte o então lançamento de Nó, mas que também serve para pensar seus outros dois livros de sonetos, diz:

Um intenso perfume anacrónico solta-se destes sonetos, não apenas por serem sonetos, essa forma fixa com todos os seus constrangimentos, mas porque actualizam uma antiga retórica, uma tropologia e uma variedade de esquemas formais - prosódicos, rítmicos,

\footnotetext{
1 Em 2019, foi publicada no Brasil, pela editora Todavia, uma antologia que recupera o título de seu livro de 2005, Os fantasmas inquilinos, seguido do subtítulo "Poemas escolhidos". Com seleção e posfácio de Mariano Marovatto, esta edição desconsidera os dois primeiros livros de Jonas: O corpo está com o rei (1997) e Moça formosa, lençóis de veludo (2002). Não há qualquer menção a esses dois volumes de modo a justificar as duas ausências, mas pode-se supor que essa decisão revela, em alguma medida, a postura do poeta em relação a suas duas primeiras investidas no campo da poesia.
} 
respeitantes à cesura do verso, sonoros, etc. Aliterações, consonâncias, assonâncias, quiasmos, anáforas, hipérboles: esta poesia é uma festa de exuberância barroca, de estranheza maneirista e de declinação clássica. Tanto nos pode remeter para Camões como para os sonetos de Shakespeare. (2014, s.p.)

Todos esses recursos levam-nos a enxergar, desde Sonótono, o primeiro livro inteiramente de sonetos do autor, a reclamação de um ofício consciente que busca na forma fixa e no metro do verso a sua possibilidade de superação como prática poética: “Soldo a métrica, malho p'ra que rime./ Toco a afiada lira, tanjo o meu aço,/ Na homérica bigorna chispa e liça." (2007, p. 12). Surge dessa imagem um poeta manipulador de aços, "um metalúrgico da Luísnava" (2007, p. 12), substância em tudo rente ao mundo moderno e elemento que oferece resistência a mãos oficinais. Aliando o mundo mitológico antigo, com referências à Homero, às sereias e à Ítaca, à metalurgia moderna - "Luísnava" acolhe tanto uma referência a Lisnave, Estaleiros Navais de Lisboa, empresa de construção e reparação naval portuguesa, quanto ecoa sonoramente a figura do poeta Luís Miguel Nava, também evocado em alguns dos vocábulos presentes no poema em questão, como "vulcão" e "lava" -, Jonas abeira duas temporalidades equidistantes em vista de se colocar como ingrediente responsável pela sua ligadura, posição que irá continuamente repetir em outros poemas, reiterando que, ao poeta, compete usar de seu olhar para fazer ver num mesmo plano de linguagem o esforço associativo da atenção ao mundo.

Essa consciência do poeta operador de substâncias é frequente em seus sonetos. Mesmo a consciência da forma, como lemos acima, reaparece de maneira impressionante em poemas como "É Outono e chove no meu soneto." (2007, p. 15) e "O sol abriu no meu soneto, o sol," (2007, p. 45). Ou ainda em: 
O meu soneto entre outras coisas serve

P'ra despistar tremor essencial

P'ra dactilocantar proporcional

No metro o que é saúde, nervo, verve.

As musas chamo às vezes só p'ra ver

Se as vejo bem; se elipse, paramnésia

A cuido já, e estilo obsessão,

Meu canto de mim mesmo ensurdecer.

É certo que os batuques dos meus dedos

São horas mais e esperam. São da amnésia,

Da folha já crestada e africana

E tu não vires, ao mantra que te engana...

O meu soneto enche-me de medos;

Uns aproveito-os bem, os outros não. (2007, p. 50).

O poema acima parece dar voz a uma tensão que a escolha do soneto com o limite de 14 versos em decassílabos aporta para a criação poética: o condicionamento do "tremor essencial" à proporção imposta pela forma. Curiosamente, o verbo utilizado para o incipit é o "servir", ou seja, ele atribui uma serventia para o seu soneto, muito distante da acepção camoniana. Da distração à observância de uma proporção, o poeta parece estar interessando numa noção de poética ligada à cabralina, quer dizer, a poética em que a transpiração é superior à inspiração, ou, pode-se também pensar, em que esta última só é convocada ocasionalmente, jocosa ou ironicamente. Preocupado com o metro, os dedos do poeta batucam para aferir o ritmo e a contagem de sílabas poéticas. Entretanto, não deixa de ser relevante que este soneto apresente irregularidade de rimas e dispense o par rimado do couplet: abba / cdec / fdgg / fe. Se porventura considerado em regra italiana (abba / cdec / fdg / gfe), a irregularidade se mantém. O "estilo obsessão", neste caso, não se atém à estrutura do soneto inglês ou italiano. Talvez se refira mais a uma obsessão por encontrar o "estilo" próprio. Longe, portanto, de defender uma poesia “seca e burguesa" (AUERBACH, 2015, p. 203), é 


\section{A forma atravessada na garganta: metasonetos de Daniel Jonas e de Paulo Henriques Britto}

com rica imaginação, energia e vigor que sua voz será moldada na quadratura do poema.

Em entrevista tornada matéria da revista Campus U.Porto (2017, p. 9-10), feita por Anabela Santos, Daniel Jonas retorna às consequências da escolha pelo soneto. Diz ele, em meio ao texto de Santos:

Não foi "a vaidade de escrever arabescos, vaidade barroca ou formal", esta aventura prendeu-se com "a precisão que o soneto traz", diz Daniel Jonas. Embora seja complexo "aceder àquela conta matemática", a verdade é que, "no final, dá-nos certas garantias e algum conforto". [...] No soneto, "chegas ao fim nos 14 versos. Tens a camisa de forças. Sabes que só podes jogar naquele pequeno recreio".

Como se viu no poema há pouco citado, a tensão entre forma e expressão no limite que esta forma implica parece produtiva para o poeta. O que para alguns poetas é uma limitação que imporia amarras prejudiciais para a criação poética, para Jonas é, por um lado, lugar de "garantias" e de "conforto" e, por outro, espaço para exercitar o desafio de atuar com essa "camisa de forças" a impedir que a mão da escrita se prolongue demasiadamente. Embate parecido é encontrado no volume Nó, no soneto cujo incipit é "Soneto não me mintas, não me inventes". Nele, como se pode perceber desde a primeira linha, é a própria forma que é interpelada:

Soneto não me mintas, não me inventes,

Não torças a verdade com as manhas

Subtis dum charlatão, deste em patranhas?

Sê claro, sê frontal, diz-me o que sentes.

Quem te viu, quem te vê... oh, tão diferente

Do que te motivou, do gozo ou pena...

Tu és como um actor levando à cena

Um texto que estudou e alegre mente. 
Quem és, que dizes tu, seu impostor!,

Que mal te reconheço... e eu juro

Que passa por mim mesmo o meu perjuro.

Não passas é de um mau imitador!

Perdoo-te o perderes-me... vai, mau espelho...

Soneto, és um logro. Argh... Estás velho! (2014, p. 19)

Formalmente, esse poema mescla o decassílabo do soneto italiano e o esquema de rimas do soneto inglês, estruturado em três quartetos e um dístico de rima idêntica. Essa mescla de referências dá a ver o amplo espectro a que o poeta se reporta, buscando na escolha formal o maior número possível de alternativas, confirmando a assertiva de Jamesson Buarque de que "Somente porque variável o soneto pode ser considerado uma forma fixa" (2015, p. 43), assertiva essa baseada no princípio "igualdade na quantidade", de Santo Agostinho.

Transformado em interlocutor, o soneto escuta as queixas do poeta, que não está satisfeito com as distorções e mentiras que ele opera naquilo que o sujeito é, ou, mais acuradamente, naquilo que ele busca exprimir. Há, dessa maneira, um descompasso entre o que o sujeito julga querer exprimir no soneto e o que o soneto, afinal, exprime. Trata-se de um "mau espelho", um "impostor", um "charlatão". Esse mau funcionamento decorre do fato de se tratar de uma forma poética ultrapassada: "Soneto, és um logro. Argh... Estás velho!". O mordaz modo como o poeta se lhe dirige não esconde que seu desejo de transparência se baseia em algo que não é da ordem do soneto (e da poesia em geral).

Como também já assinalou Maria João Cantinho, para quem a evocação ao fingimento pessoano, nesse exemplo, responde a uma "componente lúdica do poema” (2015, p. 193), Joana Meirim, em comentário a esse mesmo soneto publicado no site Jogos florais, destaca que 
o poeta retoma a tese principal da "Autopsicografia" de Fernando Pessoa, desta vez aplicada à poesia e não ao poeta - o soneto é um "fingidor", com uma acepção moral negativa que o poema de Pessoa não tem. Aqui, o soneto finge, mente, e a poesia é um "mau espelho" dos sentimentos humanos. [...] O poeta pede ao soneto que seja um bom espelho, mas sabe que, apesar do virtuosismo das rimas, do esquema rimático, de toda a técnica a que recorre no soneto, a poesia falha. A consciência desse engano e a irreversibilidade dessa situação causam uma certa melancolia, de que a interjeição onomatopaica “Argh" dá conta. (2018, s.p.)

Mas nem sempre é a demarcação espacial do soneto o aspecto que Daniel Jonas evoca quando traz para o nível textual a reflexão metapoética. Ainda em Nó, encontra-se a reflexão metapoética para além da que se volta à natureza do soneto, como neste poema em que Daniel Jonas dá um tratamento moderno ao tema do sumiço de "escritos":

Pra onde fostes, escritos que perdi?

E éreis pra serdes perdidos, enfim?

Amei-vos pobremente, qual delfim

Que de tudo se crê monarca, a si

Chamando tudo o que há, mas sem escolhas,

Uma arca que o patíbulo dissipa

E da alma faz um vento que constipa

E da árvore caduca as suas folhas?

Perdi-vos. Um anarca amou-vos. Dor

De vos perder assim, de vos saber

Pra sempre assim perdidos, um perder

De um mês qualquer, de um ano, ou mesmo um lustro

Fulgindo num salão de espelhos, cor

Ilusa, agora oblívio que eu ilustro. (2014, p. 17)

A situação a que este soneto refere parece ser a da perda de um caderno ou conjunto de diversos escritos "de um mês qualquer, de um ano". Tal sentida perda termina por germinar um outro escrito, neste caso um soneto, que não procura, por seu 
turno, servir de substituição, mas que ocupa o poeta no ofício de ilustrar - entendido aqui no sentido esclarecer, de elucidar, mas que também é acrescido do sentido de "lustro", o relâmpago incandescente a fulgir no salão de espelhos - o ausente caderno/ conjunto, agora parte do oblívio. Se o poeta busca esclarecer a natureza desses escritos ou a conjuntura que propiciou o desaparecimento, não fica claro. De toda forma, não deixa de ser interessante perceber o tratamento dispensado ao acontecimento, que inclui uma crítica ao pouco zelo do poeta, este "anarca" que apesar disso diz tê-los amado, com os escritos em questão.

Uma situação semelhante encontramos no soneto imediatamente subsequente, no mesmo $N o ́$, no qual a pauta não é exatamente a perda do que foi anteriormente escrito, mas o que não chegou a ser posto no papel. Veja-se o poema:

Dói-me o que não escrevi, e não tive em sorte,

Como um condor que, abrindo as suas braças

No mais profundo céu, chora as carcaças

Do que não teve em vida nem em morte;

Tudo o que não escrevi é passageiro,

Estação que nestas folhas não detive;

Do que escrevo sou escravo e o mantive

Pra fardo alijado ao mar negreiro

(Que os versos são só palha e porém fardo).

Sofri, mas foi por pouco que o sofri.

Melhor: murchei. Fui flor e nem flori.

Melhor errei. Honrosa a flor que é cardo.

Escrever é dor. Esquecer dor é. Que vício!

É uma hérnia na alma este ofício... (2014, p. 18)

Formalmente, esse soneto se destaca por apresentar versos hendecassílabos, em vez dos decassílabos costumeiros do volume. Além disso, apesar do esquema de rimas do soneto ser muito bem delimitado, não há, semântica e argumentativamente, uma divisão exata entre os quartetos e os tercetos. Exemplo disso 


\section{A forma atravessada na garganta: metasonetos de Daniel Jonas e de Paulo Henriques Britto}

é a continuação do argumento dos quartetos no primeiro verso do primeiro terceto. Considerando esses dois aspectos, o do sentido e o do argumento, esse verso entre parênteses termina por não pertencer aos tercetos, sendo, portanto, um acréscimo para a oitava, algo já registrado na própria natureza dos parênteses.

Tematicamente, o soneto fala das agruras inerentes ao ofício do escritor. Entretanto, nesse caso, as agruras não são da ordem do acontecimento, isto é, o que dói no sujeito é muito mais o que não acedeu a concretizar no papel. A metáfora decorre da figura do condor, uma ave que se alimenta de carcaças e de cadáveres. Essa aproximação entre o condor e o poeta dá a ver não só a possibilidade do gesto que não se consuma a contento, mas também o que lhes serve de alimento. Pode-se mesmo recordar, a esse propósito, do poema "Uma carniça", de Charles Baudelaire (1985, p. 173). Nele, a carniça encontrada é vista como um objeto depois aproximado à imagem de uma flor a se entreabrir. No poema de Daniel Jonas, ao contrário, essa "carniça" não chega a ser encontrada, o poema não vem a ser realizado. De todo modo, é nesse não se realizar do poema que ele se faz.

Outra imagem importante do poema é a da arte que pode, em certa medida, colocar correntes ao tempo: "Tudo o que não escrevi é passageiro,/ Estação que nestas folhas não detive;", diz ele, e pode-se supor que reafirma o cariz de eternidade que a arte carrega. Disso fica a ideia que, escravo de seu ofício, ofício este que lhe brinda com uma "hérnia na alma", o poeta se sente repetidamente compelido a voltar a esse ciclo vicioso ("Que vício!”) para sofrer, para errar, para enredar-se, "Que os versos são só palha e porém fardo".

Feito este pequeno percurso, é importante destacar que os sonetos de Daniel Jonas fazem parte de um projeto poético 
apresentado em forma de uma trilogia: Sonótono, Nó e Oblívio. De acordo com o autor, o objetivo era chegar à média de sonetos do autor de Hamlet: “'Quero ficar por aqui: 150 sonetos! Marca inspirada em Shakespeare (que escreveu 154 sonetos)' (risos). E lá se vai o consolo do soneto? 'É essa a intenção. Ainda bem que os escrevi, porque são o que de mais parecido tenho com marca autoral'. O resto é uma espécie de 'surtido literário'.” (SANTOS, 2017, p. 11). Tal empresa de fôlego rendeu-lhe reconhecimento como uma das vozes mais insólitas da nossa contemporaneidade. Trata-se de um poeta que mergulha nos acessos mais produtivos da linguagem: "Descuido-me da vida, abraço a obra,/ Eu vivo, quase apenas p'ra dizê-lo,/ E cada sentimento p'ra vivê-lo/ Apenas se de meu nada lhe sobra." (JONAS, 2007, p. 16).

\section{Paulo Henriques Britto e o soneto}

O caso de Paulo Henriques Britto é deveras diferente do de Daniel Jonas, principalmente no tratamento dispensado à forma como constituinte do poema. Enquanto Jonas, como se viu, busca respeitar as formas mais clássicas do soneto, reajustando ocasionalmente alguns aspectos, além do conteúdo moderno, Britto, em diversas ocasiões, desconstrói a distribuição dos versos e estrofes, mas buscando conservar o total de 14 versos tão representativo da imagem do soneto. Essa desmontagem da estrutura do soneto pode ser verificada em um poema de Macau, em que "arquitetura" e "balística" compõem um cenário de contradição em aberto. Não sendo um soneto nos moldes conhecidos, o poema apresenta 14 versos divididos em 4 estrofes com número de versos em ordem decrescente: 5-4-3-2 (abcba cdcd eae ae). 
FISIOLOGIA DA COMPOSIÇÃO

$\mathrm{V}$

É preciso que haja uma estrutura, uma coisa sólida, consistente, artificial, capaz de ficar

sozinha em pé (não necessariamente exatamente na vertical), dura

e ao mesmo tempo mais leve que o ar, senão sai do chão. E a graça toda da coisa, é claro, é ela poder voar, feito um balão de gás, e sem que exploda

na mão, igual a um fogo de artifício que deu chabu. Não. Tem que ser na altura de um morro, no mínimo, ou de um míssil

terra-a-ar. Sim. Menos arquitetura que balística. É claro que é difícil. (2003, p. 17)

Fica evidente na leitura que o sedimento desse poema é a reflexão metapoética. Isso pode ser notado desde o título, que faz mais uma vez uma citação paródica à "Psicologia da composição" de João Cabral de Melo Neto (recorde-se "Logística da composição", de Liturgia da matéria), ecoando a busca por um equilíbrio entre a rigidez da forma escolhida e a expressão que, considerada a metáfora, deve ser "mais leve que o ar". Nesse embate entre forma e conteúdo encontra-se desde logo a forma tolhida de sua estrutura "original", cedendo espaço para modificações de cunho expressivo, sem deixar de revelar a continuidade de um apuro formal que se sustente no apelo à simetria. Isso fica evidente também na seção "Sete sonetos simétricos", em que o autor evoca tanto as formas já catalogadas do soneto, como o modelo shakespereano (2003, p. 45), quanto apresenta novos desenhos para as estrofes, o que se verifica em 
um poema iniciado e terminado com dísticos de rimas idênticas (aa aa) e ao centro uma estrofe de dez versos com rimas alternadas (2003, p. 43), ambos escritos em língua inglesa, provavelmente para dialogar com essa tradição que considera o dístico final em rima única, agora duplicado e figurando nos dois extremos do poema. Logo na sequência da mesma seção, encontramos também um jogo de simetria, no poema "VI" (2003, p. 46), mas com um fluxo diferente, iniciando e terminando com dísticos rimados e composto de cinco estrofes (2-3-4-3-2).

Essa proliferação de jogos formais como questionamento aos estados da poesia contemporânea remete diretamente para o papel da tradição na poética sonetista do autor. No seu segundo livro, Mínima lírica (2013b, p. 98), encontramos a conversa estabelecida com o poema "Dúvidas apócrifas de Marianne Moore" de João Cabral de Melo Neto, em que a dúvida sobre a escrita do eu ou das coisas motiva o poema. Britto, no que chama "Indagações", constrói um poema recuperando as dúvidas cabralinas e as faz ecoar, tal como no poema da mesma seção dedicado a Augusto de Campos (2013b, p. 99). A relação produtiva que a poesia de Britto estabelece com a de João Cabral de Melo Neto é muito bem assinalada em artigo do poeta e crítico Antônio Carlos Secchin. Para ele, ambos são "poetas da sintaxe" (2015, p. 313), isto é, ambos prezam pelo poema como um objeto a ser construído, sem arroubos imagéticos, o que chama de "fulgor ocasional" (2015, p. 313). Contrariando a si mesmo, quando diz que "O forte da vida// não é a originalidade" (2007, p. 79), Paulo Henriques Britto consegue se alimentar de João Cabral e ainda assim manter sua voz pessoal.

Outra ruminação sobre a criação poética encontra-se no segundo soneto da seção "Art Poétique", de Tarde: 
II

Diário de viagem sem viagem ou carta sem nenhum destinatário: palavras que, no máximo, interagem com outras palavras do dicionário.

Um escrever que é verbo intransitivo que se conjuga numa só pessoa. Um texto reduzido a substantivo menos que abstrato: se nem mesmo soa,

como haveria de querer dizer alguma coisa que valesse o vão e duro esforço de fazer sentido?

Por outro lado, a coisa dá prazer.

Dá uma formidável sensação (mesmo que falsa) de estar sendo ouvido. (2007, p. 54)

Com organização estrófica e decassílabos nos moldes italianos, esse soneto utiliza-se de referências caras à história da poesia ocidental, especialmente o eco do famoso verso de Paul Verlaine, "De la musique avant toute chose", antecipado pelo título homônimo da seção, mas também a ideia de que a escrita é um jogar com as palavras, numa investida intransitiva, muito próxima da assertiva mallarmeana de que é com elas, as palavras, que se fazem os versos, não com as ideias (VALÉRY, 2012, p. 107). Não é de se desconsiderar, ademais, que esse mesmo poema de Verlaine tenha inspirado imageticamente a quinta parte da "Fisiologia da composição", anteriormente referida, precisamente quando diz: "E a graça toda/ da coisa, é claro, é ela poder voar,/ feito um balão de gás". Mais ao final da "Arte poética" do simbolista francês lê-se: "Música ainda, e eternamente!/ Que teu verso seja o vôo alto/ Que se desprende da alma no salto/ Para outros céus e para outra mente." (1986, p. 149). 
Essa discussão sobre os rastros da tradição na poesia do autor de Trovar claro é deveras produtiva se se pensar que esses poetas evocados para o indistinto espaço que o poema inaugura são todos de uma ordem de grandeza fundacional, isto é, são todos eles poetas fortes, na acepção bloomiana desenvolvida em A angústia da influência (1973). Aliando-se a uma moderna tradição metapoética, os sonetos de Paulo Henriques Britto, desde o livro de estreia, Liturgia da matéria, pensam a si mesmos como objetos em processo de composição, de feitura. $\mathrm{O}$ primeiro dos "Dez sonetos sentimentais" do livro de 1982 é um desses casos exemplares:

I

Se por acaso a mão que escreve toca uma coisa qualquer a que é negado o se deixar pegar, e se essa mão desentranha do fundo da caneta um desses pedaços de consciência que não se deixa nunca ultrapassar a linha dos dentes, se a mão inventa alguma coisa feia e porca, um verme que se debate entre as linhas da pauta como quem quer morrer mas não consegue, e se no instante antes do risco mortal a mão hesita e espera, como quem teme uma certeza, ou sente no fundo do medo uma espécie de compaixão? (2013b, p. 23)

Inicialmente, convém destacar a irônica designação dessa série que já principia com um soneto longe do sentido corrente de "sentimental". O mais próximo que pode haver da emoção aventada é a "espécie de compaixão" que encerra a longa interrogação de que se faz o soneto. Tudo posto em suspensão pela questão que levanta, o poema tende mais a ensaiar um 


\section{A forma atravessada na garganta: metasonetos de Daniel Jonas e de Paulo Henriques Britto}

processo de ir e vir, um processo dinâmico, portanto, que é inerente ao fazer poético. Para essa dinamicidade contribui a presença central da "mão que escreve", ao meio chamada também de "mão [que] inventa". Os gestos de escrever e de inventar resultam na imagem de que o poema é um objeto elaborado pelo poeta, pela mão do poeta, reforçando essa ideia de que se trata de algo sempre fugidio, em que "é negado/ o se deixar pegar". Outro ponto interessante a se evidenciar é o momento em que a "mão hesita" perante o "risco mortal", enfatizando a relação nada apaziguadora entre a escrita e o fim da escrita, o fim não do poema, mas o fim de uma relação de criador com criatura, "como quem/ teme uma certeza".

Enquanto no exemplo acima o poeta aparece como detentor de seu membro superior, no poema de abertura da série "Sete estudos para a mão esquerda", de Trovar claro, a "mão que escreve" adquire uma certa independência em relação ao sujeito que escreve:

I

Existe um rumo que as palavras tomam como se mão alguma as desenhasse na branca expectativa do papel

porém seguissem pura e simplesmente a música das coisas e dos nomes o canto irrecusável do real.

E nessa trajetória inesperada a carne faz-se verbo em cada esquina resolve-se completa em tinta e sílaba em súbitas lufadas de sentido.

Você de longe assiste ao espetáculo.

Não reconhece os fogos de artifício, as notas que ainda engasgam seus ouvidos.

Porém você relê. E diz: é isso. (1997, p. 19) 
Percebe-se desde logo que a distribuição dos quartetos e dos tercetos está invertida. Essa inversão se repete em todos os sete poemas da série e pode-se imaginar que ela se deve à mão esquerda mencionada no título: sonetos escritos com a mão esquerda saem diferentes dos da mão mais comum, a direita. E a mão tem papel central nessa peça. $O$ poeta fala de uma "trajetória inesperada" do poema, à revelia de uma possível tentativa de domínio do que vai para o papel. Reafirma, portanto, a ideia de que há algo na escrita do poema que ultrapassa a razão daquele que escreve, que "de longe assiste ao espetáculo", como se não tivesse parte na natureza dos "fogos de artifício". Com alguma surpresa o resultado final lhe agrada, é irretocável. Tanto no soneto sentimental quanto neste estudo para a mão esquerda encontramos a reverberação de uma poética que se revela enquanto se faz, num gesto de "Escrever a contrapelo do papel" (1997, p. 31).

Mas é talvez em Formas do nada que Paulo Henriques Britto se debruça mais intensamente na seara dos metapoemas. Destaque-se o consolo metalinguístico do poema de abertura (2012, p. 11), enfatizando que a única saída para o poeta quando se depara com as agruras mundanas é a linguagem poética, seu refúgio. Ou ainda a série "Oficina", que sugere desde logo um local para a prática poética, uma aprendizagem nunca conclusa, em que é preciso "escrever por determinação", isto é, tornar essa relação com a escrita uma visita a que se não pode furtar, sob quaisquer pretextos. Veja-se o segundo soneto da série:

II

Umas às vezes aparecem sem nem ter sido convocadas. Não têm razão, origem, nada que se calcule, pese ou meça. 
E mesmo assim elas se impõem com a força de quem não admite contra-argumentos nem limites, nem desculpas, nem exceções.

Há que deixá-las entrar sempre, por dever de hospitalidade

e temor supersticioso:

pois não se bole impunemente com a contingência, com o caso, esses deusinhos perigosos. (2012, p. 14)

Seguindo um argumento parecido com o do poema anteriormente citado, em que há a tematização de uma "trajetória inesperada" na confecção do poema, este centra-se no surgimento de palavras que invadem a escrita, "sem nem ter sido convocadas". Obstinadas, essas palavras encontram no poema um lugar de sentido, mesmo que ele escape ao poeta, que termina, "por dever de hospitalidade/ e temor supersticioso", aceitando a contingência e o acaso que inelutavelmente farão parte da constituição do poema, como se uma palavra puxasse a outra e assim por diante, e a razão tivesse um papel menos regulador nesse processo criativo. Essa leitura implica, naturalmente, a aceitação de certa ironia, dada a ver no encerramento do soneto quando menciona os "deusinhos perigosos" (contingência e acaso). O tom de blague desfaz a seriedade do tema apresentado nos treze versos, retirando-lhe a pretensão de continuar a emular, sob os mesmos termos, a constante imagem do problemático e misterioso processo de criação poética. De toda forma, é interessante perceber como esse olhar para a questão da escrita é recorrente na poética de Paulo Henriques Britto e assume diversas camadas que, ao cabo, constituem uma das mais visitadas produções deste princípio de século. 


\section{A forma atravessada na(s) garganta(s): à guisa de con- clusão...}

Paul Valéry, a propósito dos sonetos de Degas, disse:

Nada, em literatura, é mais próprio do que o soneto para opor a vontade à veleidade, para fazer sentir a diferença da intenção e dos impulsos em relação à obra acabada; e, principalmente, para obrigar a mente a considerar o fundo e a forma como condições iguais entre si. Explicome: ele nos ensina a descobrir que uma forma é fecunda em ideias, paradoxo aparente e princípio profundo em que a análise matemática tirou algum partido de seu poder prodigioso. (VALÉRY, 2012, p. 105)

É possível perceber, no decurso desta breve reflexão sobre os metasonetos de Daniel Jonas e de Paulo Henriques Britto, modos e maneiras diferentes de se retrabalhar a forma fixa soneto, de nela perceber não o limite intransponível a que o poeta deve aceitar, mas o campo fértil que a consideração de "fundo" e "forma" podem aportar na criação poética. Nesse sentido, buscou-se operar a conjugação, ainda que pela produtiva diferença, dessas duas poéticas representativas do que há de mais relevante na poesia de língua portuguesa.

\section{Referências}

AUERBACH, Erich. Introdução aos estudos literários. Tradução de José Paulo Paes. Posfácio de Marcus Mazzari. São Paulo: Cosac Naify, 2015.

BAUDELAIRE, Charles. As flores do mal. Tradução e notas de Ivan Junqueira. Rio de Janeiro: Nova Fronteira, 1985. 
BOCAGE, Manuel Maria Barbosa du. Poesia. Leodegário A. de Azevedo Filho (Org.). Rio de Janeiro: Agir, 1985. (Coleção Nossos Clássicos, v. 115)

BUARQUE, Jamesson. Soneto como variação fixa formal. Revista Texto Poético, Goiânia, v. 11, n. 19, p. 41-72, $2^{\circ}$ sem. 2015. Disponível em: http://textopoetico.emnuvens.com.br/rtp/ article/view/324. Acesso em: 14 fev. 2020.

BRITTO, Paulo Henriques. Formas do nada. São Paulo: Companhia das Letras, 2012.

BRITTO, Paulo Henriques. Macau. São Paulo: Companhia das Letras, 2003.

BRITTO, Paulo Henriques. Matador de passarinho. Entrevistador: Skylab. Veiculado no Canal Brasil, no dia 08 de julho de 2013a. Disponível em: https://www.youtube.com/ watch?v=Rqwzq0_FNZM. Acesso em 09 out. 2019.

BRITTO, Paulo Henriques. Mínima lírica. São Paulo: Companhia das Letras, 2013b.

BRITTO, Paulo Henriques. Tarde. São Paulo: Companhia das Letras, 2007.

BRITTO, Paulo Henriques. Trovar claro. São Paulo: Companhia das Letras, 1997.

CAMÕES, Luís de. Lírica completa II (Sonetos). $2^{\mathrm{a}}$ ed, revista. Prefácio e notas de Maria de Lourdes Saraiva. Lisboa: Imprensa Nacional - Casa da Moeda, 1980. v. 2.

CANTINHO, Maria João. Recessão crítica a $N o ́$ - Sonetos, de Daniel Jonas. Colóquio/Letras, Lisboa, n. 190, set. 2015. p. 191-194.

ELIOT, T. S. Tradição e talento individual. In: Ensaios. Tradução de Ivan Junqueira. São Paulo: Art Editora, 1989. p. 37-48.

GUERREIRO, António. Versos de puro nada. Público, Ípsilon, Lisboa, 08 ago. 2014, s.p. Disponível em: https://www. 
publico.pt/2014/08/08/culturaipsilon/critica/versos-de-puronada-1665582. Acesso em: 02 out. 2018.

JONAS, Daniel. Daniel Jonas: o antiquado que é o mais alto da poesia portuguesa. Entrevista a Joana Emídio Marques. Observador, Caderno Cultura, Lisboa, 20 abr. 2017. Disponível em: https://observador.pt/2017/04/20/daniel-jonas-o-antiquadoque-e-o-mais-alto-da-poesia-portuguesa/. Acesso em: 11 out. 2018.

JONAS, Daniel. Nó - sonetos. Porto: Assírio \& Alvim, 2014.

JONAS, Daniel. Os fantasmas inquilinos. Lisboa: Cotovia, 2005.

JONAS, Daniel. Resposta ao Inquérito Poesia e Resistência (Portugal) realizado por Ana Luísa Amaral, Joana Matos Frias, Pedro Eiras e Rosa Maria Martelo. LyraCompoetics / Instituto de Literatura Comparada Margarida Losa, 2012. Disponível em: http://ilcml.com/inquerito-poesia-e-resistencia-portugal/. Acesso em: 28 ago. 2019.

JONAS, Daniel. Sonótono. Lisboa: Cotovia, 2007.

MEIRIM, Joana. Comentário a "Soneto não me mintas, não me inventes.”, de Daniel Jonas. Jogos florais. 27/01/2018. Disponível em: https://www.jogosflorais.com/poemas-de-agora/2018/1/27/ soneto-no-me-mintas-no-me-inventes?rq=daniel $\% 20$ jonas. Acesso em: 20 jun. 2019.

MILTON, John. The poems of John Milton. Edição de John Carey e Alastair Fowler. Londres: Longmans, 1968.

SANTOS, Anabela. Alumni (Daniel Jonas). Campus U.Porto, n. 1, p. 8-11, 2017. Disponível em: https://issuu.com/uporto/ docs/campus_up_1/8. Acesso em: 07 out. 2019.

SARAIVA, António José. Introdução à literatura portuguesa. São Paulo: Companhia das Letras, 1999.

SECCHIN, Antônio Carlos. Paulo Henriques Britto, desleitor de 
João Cabral. Estudos Avançados, São Paulo, v. 29, n. 85, p. 313-317, Dec. 2015. Disponível em: http://www.scielo.br/scielo. php?script=sci_arttext\&pid=S0103-40142015000300020\&lng $=$ en\&nrm=iso. Acesso em: 12 Set. 2020.

VALÉRY, Paul. Degas dança desenho. Tradução de Christina Murachco e Célia Euvaldo. São Paulo: Cosac Naify, 2012.

VERLAINE, Paul. Art poétique/Arte poética. Tradução de Augusto de Campos. In: CAMPOS, Augusto de. O anticrítico. São Paulo: Companhia das Letras, 1986. p. 146-149. 